UDK 785 (497.12)

\title{
K VPRAŠANJU SLOVENSKOSTI SLOVENSKE INSTRUMENTALNE GLASBE
}

\author{
Andrej R i j a v e c (Ljubljana)
}

Pričujoče pisanje se zdi dvojno simptomatično. Tako glede same teme kot zavoljo načina, $\mathrm{s}$ katerim se pristopa $\mathrm{k}$ njeni osvetlitvi, čeprav se tako tema kot način njene obdelave medsebojno pogojujeta in dopolnjujeta. $\mathrm{V}$ znanosti je ponavadi pač tako, da predmet raziskave narekuje pristop in ne obratno, ker lahko sicer vodi v toge ali vsaj neprimerne rešitve. Navzlic temu bi kazalo omenjeno simptomatičnost nekoliko razložiti.

Lahko bi se pojavil očitek, da vprašanje nacionalnih potez in to še povrhu v instrumentalni glasbi pač ni znanstveno, muzikološko vprašanje in da si zato ni obetati »uștreznih « rezultatov. Ne glede na problem »ustreznosti«, ki celo v najbolj eksaktnih vedah ne vodi do dokončnosti, se zdi tako gledanje napačno. $\mathrm{Na}$ eni strani nagiblje $\mathrm{k}$ pozivitizmu, na drugi pa si neutemeljeno prilašča pravico razsoje, s kakšnimi problemi bi se znanost smela ukvarjati, ko je na dlani, da praktično ni vprašanja, ki bi ne moglo biti tudi znanstveno. Drugo je seveda vprašanje, ali lahko določena znanost $\mathrm{v}$ okviru svojih tradicionalnih prijemov celovito odgovori na zastavljena vprašanja. A dokler so le-ta tu, ne smejo predstavljati tabuja, pa čeprav je že vnaprej zavoljo narave teme jasno, da jih ni možno dokončno, vsestransko empirično in racionalno raziskati, se pravi "rešiti brez ostanka «. ${ }^{1}$

Kar zadeva način pisanja, za katerega si avtor nikakor ne domišlja, da se mu je posrečil, je treba reči, da mu je bilo pri iskanju primernega pristopa v vzpodbudni koincidenci v korist Janka Kosa razmišljanje v razpravi »Esej in Slovenci«, ko za preteklost in sedanjost ugotavlja »neslovenskost « tega načina, oziroma točneje, forme takega besedovanja, in med drugim pravi: »...za bistveno rast eseja manjkajo $\mathrm{v}$ dobršni meri primerni pogoji, med njimi zlasti na vse strani sproščena, razmahnjena in razvita osebnostna subjektivnost, ki je gotova sama v sebi, tako da se ji ni potrebno ves čas preveč krčevito oklepati te ali one dogmatike, strogo določene ideologije, filozofskih sistemov in sistematične znanstvenosti; skratka, ki lahko o svojih temah razmišlja iz neposrednjega doživetja, vpogleda in izkušnje... pa tudi ne tako, da bi neprestano poučevala in vzgajala bralca ali pa se polemično borila $\mathrm{z}$ nasprotniki za svoj vnaprej zastavljeni prav «. ${ }^{2}$ Se pravi, da se pravzaprav $z$ izrazito »neslovenskim « pristopom lotevamo tematike, katere opredelitev naj bi $\mathbf{v}$ svojem rezultatu navrgla vsaj nekaj slovenskosti. Zdi se namreč, da bi tradicional-

1 Supičić I., Estetika evropske glazbe, Zagreb 1978, 107.

2 Prim. Sodobnost, XXVII/1979, št. 1, 49. 
no »slovenski « pristop, pri čemer $\mathrm{v}$ tem primeru prepuščam bralcu semantično razlago epitetona »slovenski «, ne vodil niti v bližino vprašanja. Kritika slovenskih značajskih potez? Morda. Kar pa vsekakor upravičuje domnevo, da bo izbrana »contradictio in adiecto « vsaj malo načela problem, $\mathrm{ki}$ je še tako prisoten $\mathrm{v}$ našem in tujem razmišljanju o slovenskem instrumentalu.

Doslej sta o vprašanju nacionalnega $\mathbf{v}$ nakazanem smislu pri nas pisala med drugimi predvsem Borut Loparnik ${ }^{3}$ in podpisani. ${ }^{4}$ Medtem ko je prvi sicer povezal svoje razglabljanje na navidezno »dostopnejši« vokal, a pri tem iskal izvenglasbene nacionalne komponente, $\mathrm{ki}$ in kakor naj bi odsevale iz zborovskega opusa Marijana Lipovška, so drugega zanimali vzvodi, ki nacionalno v evropski glasbeni kulturi "povišujejo» na raven internacionalnega. Tokrat je tema glasbeno konkretnejša in zato tudi racionalno abstraktnejša, vsekakor težja, kot so jo na povedno razložljivejših področjih umetnosti nekateri pisci bleščeče zastavili in temu primerno tudi rešili. ${ }^{5}$

Neposredne pobude za sestavek so se nabirale že dobro desetletje: od inozemskih poročil s koncertnih prireditev ob Desetem kongresu Mednarodnega muzikološkega društva (Ljubljana 1967), v katerih med drugim beremo, da je na koncertu Društva slovenskih skladateljev tega poročevalca prevzel »muzikantski element « izvajanih sodobnih del, drugi da je zopet v njih videl oziroma slišal »mediteransko-slovansko varianto avantgardizma ${ }^{6},{ }^{6}$ do drobcev iz slovenske glasbene preteklosti, ki beležijo, da je barva znamenitega liričnega tenorja Josipa Rijavca pripadala »nebu južno od Alp «, ${ }^{7}$ ali na primer, da je bil »Jenko skoraj avtodidakt« in "zato tako izklesano slovenski «. ${ }^{8}$ In tako dalje in tako naprej. Primerov veliko, ki včasih nepremišljeno, a največkrat intuitivno pravilno potrjujejo trditev, da »određena glazba... može označavati ili izražavati neke izvanmuzičke sadržaje, pa se prema tome može smatrati označujućom, ili čak ekspresivnom, i to ako se pri slušanju ta glazba može percipirati ne samo kao glazba nego i doživjeti opravdano povezujući njezin muzički sadržaj s nekim izvanmuzičkim značenjima ili sadržajima «, 9 oziroma, po besedah Leonarda B. Meyerja: "Music may be meaningful because it refers to things outside itself, evoking associations and connotations relative to the world of ideas, sentiments and physical objects «. ${ }^{10}$ Seveda je to samo neobvezen racionalni dodatek sicer imanentno glasbenega doživljanja. In vendar, po obeh poteh - od naslovnih značilnosti do posebnosti tretiranja zvočne fakture - tudi v instrumental prodirajo nekatere poteze, ki odsevajo take, težko dokazljive in še težje racionalno posplošljive kategorije, kakršne so geografske in klimat-

3 O nacionalnom u Lipovšekovim horskim kompozicijama, Zvuk 1970/108, 344-351.

4 Notes towards the National and International in Music, International Review of the Aesthetics and Sociology of Music. Vol. VII. No. 1 - 1976, 83-87.

5 Prim. Pevsner N., The Englishness of English Art, Harmondsworth 1976.

- Gl. mapo »Kritike«, Arhiv 10. kongresa Mednarodnega muzikološkega društva, PZE za muzikologijo, Filozofska fakulteta, Ljubljana.

7 Koncertni list Slovenske filharmonije, 1969/70, št. 8, 9.

8 Spendal M., Razvoj in značilnosti slovenskega romantičnega samospeva, disertacija, Ljubljana 1979, 42.

9 Supičić I., ib., 108.

10 Music, the Arts and Ideas, Chicago - London 1967, 6. 
ske značilnosti, ${ }^{11}$ rasne posebnosti, ki so $\mathrm{v}$ polpreteklosti doživele absurdno izpeljavo, ${ }^{12}$ »duh « časa in končno, a ne nazadnje, skozi prizmo skladateljske osebnosti projicirane ter bolj ali manj realizirane nacionalne karakteristike - same spremenljivke, ki so glede na omejeno prevedljivost glasbenega medija zlasti $v$ instrumentalu še toliko bolj subjektivno interpretativne kot pa objektivno apologetične narave. A ker so nedvomno prisotne, vabijo k soočanju. Morebitno premajhno sistematičnost in premajhno poglobljenost $v$ iskanju ter določanju nacionalnega bo treba pri tem pripisati skicirajočemu pristopu, ki niti more niti hoče biti popoln ali dokončen. Za slednje je vedno prezgodaj.

Kdaj je v evropski glasbi prvič zazvenela slovenska struna, kdaj je verzirani poslušalec prvič postal pozoren na nove, drugačne, ali vsaj v odtenku posebne zemljepisne oziroma nacionalne koordinate zvočno zaznavnega, ne bo nikoli možno dognati. Ali se je to zgodilo že ob Gallusovem motetu Praeparate corda vestra, katerega začetek se pokriva s slovensko ljudsko Šel sem, šel čez gmajnico? Ali morda ob kakšnem značilnem melodičnem obratu v kateri izmed Ivančičevih simfonij ali divertimentov? Ob Novakovem Matičku? Ne more biti nobenega dvoma, da nacionalnih posebnosti ne gre samo enačiti $z$ uporabo slovenskega jezika oziroma, če ostanemo na ožjem instrumentalnem področju, $\mathrm{z}$ razmeroma neproblematično dokazljivimi ritmičnimi in harmonskimi značilnostmi ter še bolj zgovornimi potezami melodične dikcije. Pri zastavljenem hotenju gre za nekoliko več; gre pravzaprav za nakazovanje tistih »okrasnih pridevkov«, ki bi jih navkljub prekrivanju s podobno označenimi (občečloveškimi) ter $\mathbf{v}$ končni konsekvenci izvenglasbenimi značilnostmi drugih, to je neslovènskih, instrumentalov in torej brez samozvanega, slovenskega »copyrighta « lahko v posameznih konkretnih primerih interpretirali kot verjetni ali vsaj možni odsev določenih nacionalnih potez, ki same po sebi sicer niso dane v samem zvočnem gradivu, ampak so posledica določenega, tako ali drugače, $v$ času in prostoru »slovensko« pogojenega traitementa.

Glasbeno zgodovinopisje nas uči, da so bili podobno kot pri mnogih drugih evropskih narodih šele $\mathrm{z}$ romantiko položeni temelji samostojni slovenski glasbeni kulturi. Barometer slovenskosti je začel dialektično beležiti rast, nihanja in padce obrisov nacionalnega, ki se je polagoma izvijalo iz spon utilitarizma, variante, ki je umetniško in razvojno manj zanimiva. S trojico B. Ipavec-Foerster-Gerbič, zlasti s prvim in to na področju vokala, smo se znova približali ravni sočasnega evropskega glasbenega ustvarjanja. Instrumental je še nekoliko zaostajal. Kljub temu je začel beležiti nekatera vredna dela: briljantni Foersterjevi koncertni parafrazi priljubljenega slovenskega napeva Po jezeru bliz' Triglava (1870-74) se je proti koncu stoletja pridružila še, zavoljo svoje zgoščene liričnosti, slovensko značilnejša Zagorska (1890-92). In nato - Ipavčeva Serenada za godalni orkester (1898), ta postklasicističen in obenem očarljivo lahkoten instrumentalni zapoznelec, katerega žlahtni melodiki ne manjka slovenskih prvin, ta blagohoten odsev čitalniške dobe in njenega samozadovoljnega družabnega življenja! Njen sodobnik Gerbič - se je instrumentalno odrezal šele pozneje, z Jugoslovansko rapsodijo (1907) in Jugoslovansko balado (1910) ter Lovsko simfonijo (1915), ki ji resnost

11 Szabolcsi B., Grundzüge einer Musikgeographie, v: Bausteine zu einer Geschichte der Melodie. Budapest 1959, 292 sl..

12 Wulf J., Musik im Dritten Reich, Gütersloh 1963, 313 sl.. 
pristopa v romantičnem žanru sicer povečuje tragiko zapoznelosti, neredkega merila slovenskosti, ki pa na področju čistega instrumentala predstavlja obenem prvo resnejše preseganje malih form, ali $\mathrm{z}$ drugimi besedami povedano,preseganje vse predolgo značilne in do samodopovedovanja povzdignjene nalepke o nekakšni slovenski mini-izpovednosti oziroma glasbenoizpovednem vrtičkarstvu v smislu »klein, aber fein «.

A medtem so se stvari tudi instrumentalno krepko premaknile; tako v območju umetne glasbe kot na področju njene lahkotnejše posestrime, ki jo ne gre zametavati. V mislih imam Viktorja Parmo, ki se je zelo zgodaj vključil v slovenska glasbena prizadevanja: povsod, kjer je služboval - od Kočevja in Kranja, Krškega in Litije do Kamnika in Črnomlja in še kje, je bil glasbeno aktiven, ustanavljal orkestre in najširšim plastem nudil boljšo vedro glasbo. Oboževan od občinstva je rafiniral slovensko muzikalno dušo, vendar ne $v$ smeri avsenikovske vrnitve $\gg k$ (slovenski?) naravi «, ampak prav obratno, v smeri uglajevanja njenih avtohtonih potez. Resno ustvarjanje je imelo seveda odgovornejše naloge postopnega vzporejanja z evropskim instrumentalom. Anton Lajovic ga je značilno zastavil že s svojo lirično Sanjarijo za klavir (1900), nakar so orkestralna dela od Adagia (1900) dalje, vključno s Pesmijo jeseni (1938), samo še stopnjevala zadržano elegičnost. Caprice (1922) v svojem poveličevanju petdelnega folklornega utripa sicer odstopa od te osnovne čustvene naravnanosti, a obenem prinaša nekakšen pastozno impresionističen nadih, ki se zlasti v lirično usmerjenem godalnem zvoku mimo Adamičevih Ljubljanskih akvarelov (1925) vleče skozi mnogotero skladbo Lucijana Marije Škerjanca tja do Prélude melancolique (1938) kakega Jurija Gregorca daleč $\mathrm{v}$ povojni čas - poteza, ki nadživi svojo stilno upravičenost in prehaja že na področje nacionalne posebnosti. Kljub temu je ugotoviti, da je Janka Ravnika trdna povezanost $\mathrm{z}$ naravo že pred I. svetovno vojno razslojila nakazano slovensko liričnost, ki s klavirskimi skladbami, kot so Večerna pesem (1911), Moment, Dolcissimo, Čuteči duši (vse 1912), »ne ostaja na ravni skromne idiličnosti ali spodobnega vzhičenja, kakor je bilo do tedaj, temveč se odpira nasproti veliko globljemu doživljajskemu svetu in jemlje iz njega močno meditativno zamaknjenost, pa tudi vzburjeno strastnost, ki jo oblikuje do izredno napetih dramatičnih vzponov in viškov «. ${ }^{13}$ Vendar so bili na pohodu novi časi, tako da virtuozno hitri Grand valse caractéristique (1916) in zamišljeno počasni Valse melancolique (1928) že predstavljata pogled nazaj: v prvem primeru s harmonsko zaostrenim koncertantnim zamahom odmikajočega se 19. stoletja, $v$ drugem $\mathrm{z}$ nekoliko tmurno naravnanim odmevom na elegantne meščanske čase, ki pa se na Slovenskem niso nikoli v celoti realizirali.

Marij Kogoj je slovenski glasbi razkril ekspresionistično izpovednost, $\mathbf{s}$ čimer je samo stopnjeval v njej skrito, latentno bolest. Znan je njegov izrek: „Glasba ni zunanjost in površina, nego je dno«, ki ga je še kako resno pojmoval: pisal je in vedno znova kaj dopisal, delal in dodelaval, trgal se in mučil, da bi se dokopal do tistega, stopnjevano prizadetega izraza, ki bi ga lahko osvobodil in mu prinesel estetsko zadoščenje in človeško olajšanje. Bolečina, ta občečloveška in obenem slovenska, a v potencirani obliki razmeroma individualizirana kategorija, je prisotna tudi v večini skladateljevih maloštevilnih instrumentalnih del. Kot bolj ali manj zakrita pobuda tiči za takimi skladbami, kot so Piano (1913-21). Andante za

${ }^{13}$ Lipovšek M., v: Janko Ravnik, Klavirske skladbe, Ed. DSS 537. 
violino in klavir (1924) in celo Malenkosti (1932) za klavir, ki zgostijo izpoved na še bolj omejen zvočni prostor. Primerjali bi ga lahko s tradicionalnim slovenskim rožnim vrtičkom, a tokrat $\mathrm{v}$ introvertiranih fantazmagoričnih barvah - seme, ki bo še desetletja klilo na slovenskih instrumentalnih tleh (Koporc, Ukmar) tja do najmlajših.

V tej in taki konstelaciji se zdi Slavko Osterc s svojim obsežnim in raznovrstnim opusom nekako »neslovenski «, pri čemer moramo glede na izbrano temo obiti najrazličnejše njegove, $\mathrm{k}$ polikulturni evropski enakopravnosti usmerjene, prodorne aktivnosti. Vendar so tudi kompozicije same dovolj zgovorne. Ob jasnem pristopu in trezni urejenosti, ki pritiče skladateljevemu delno neobaročnemu oziroma neoklasicističnemu konceptu, prihajajo na površje doslej neznane, komaj ali vsaj premalo znane poteze slovenskega instrumentala: lahkotna duhovitost, sarkazem, groteska, drznost, širokopoteznost in zavoljo ne vedno obvladljivih načrtov občasna nedodelanost, a pri vsem tem nekakšna jedra mobilnost, ki je zajadrala na svetovna morja in ob kateri se sicer kvalitetna škerjančevska spevnost vedno znova "pravočasno « umakne kataklizmi in umira v svojem zvočnem leporečju, pa naj gre za slednjega simfonije ali komorna dela, koncerte ali vzorne klavirske kompozicije od Sedmih nokturnov (1935) dalje. Kakor da bi Osterc s skladbami, kot so Silhuete za godalni kvartet (1928), Suita za 8 instrumentov (1928), Kvintet za pihala (1932), II. godalni kvartet (1934), Mouvement symphonique (1936), Nonet (1937) in podobne stvaritve, razširil diapazon značajskih potez slovenskega instrumentala. Vendar je to bolj razširitev v smeri Evropa-Slovenija kot pa obratno; tako da je element tradicionalnejše slovenskosti - od folklornega do liričnega, čemur tudi takšna osebnost, kot je bil Osterc, ni mogla uiti - iskati bodi v izjemah à la Religioso iz Suite za orkester (1929) bodi v nekaterih kompozicijah na pragu skladateljeve prezgodnje smrti, tako na primer v simfonični pesnitvi Mati (1940) ali v Sonati za violončclo in klavir (1941).

Zaradi delnega zamudništva je slovenska instrumentalna glasba dograjevala svojo podobo s tematiko, ki bi bila bolj značilna za 19. stoletje, še pozno v 20. stoletje. Tako smo priča navideznega neskladja: ali, da je zadevni glasbeni jezik glede na drugod preseženo naslovno tematiko že skoraj nekoliko »premoderen «, ali pa, da je ta in taka programskost že obsoletna in posebnost "Evropo « dohitevajočih kultur. Gre namreč za nekatere zgodnejše kompozicije Matije Bravničarja, kot so Hymnus Slavicus (1931), Kralj Matjaž (1932) ali na primer Plesna burleska (1932), pa vrsta v slovensko zemljo zakoreninjenih simfoničnih pesnitev Blaža Arniča, kot so Ples čarovnic (1936), Pesem planin (1940) in podobno. Ker pa se omenjena tematika bolj ali manj očitno pojavlja vse do najnovejšega časa, kaže, da imamo opraviti s še neizživetim področjem, morda celo s stalnico slovenskega instrumentala. Spomniti je treba samo na Arničeve povojne simfonije in na njegove nadaljnje simfonične pesnitve - Gozdovi pojejo (1945), Povodni mož (1950), Divja jaga (1965), ali na Bravničarjevega Kurenta (1950), Drugo simfonijo in Re (1951) in Tretjo simfonijo-stretto (1958). Pri tem se seveda kaže zavedati dejstva, da so šele s pregonom dur-molovskega občutja lahko prišle do veljave vse ritmične, harmonske in melodične posebnosti folklore posameznih slovenskih pokrajin: ob Pahorjevem začetnem, od Osterca spočetem modernizmu istrska ljudska melodika v Istrijanki (1951), ob Švarovem izhodiščnem evropskem avantgardizmu skladba, kakršna je Sinfonia da camera in modo istriano (1957), ob igrivo-objestnem, muzikantskem imenovalcu Pavla Šivica njegova Medjimurska in kolo za sim- 
fonični orkester (1945-46), da niti ne omenjamo slovenske rapsodije za godala Pavla Merkùja Ali sijaj, sijaj, sončece (1977), ki je kot ena najboljših slovenskih skladb svoje vrste $\mathrm{v}$ nekoliko priostreni, neobrittnovski glasbeni govorici še pred nedavnim odlično ujela patino slovenske grude, posebno tiste $\mathrm{v}$ Benečiji.

Pristna slovenska nota seveda ni dana sama po sebi, če skladatelj "pade v folkloro", ampak s tem, če črpa "glasbene domisleke iz sebe, iz svoje notranjosti ; » ker je Slovenec, ni mogoče, da bi komponiral v kakem drugem tonu kakor v pristno slovenskem «, je januarja 1939 pisal Slavko Osterc. ${ }^{14}$ Zato merilo slovenskosti ne more biti $\mathrm{v}$ mehaničnem premem sorazmerju s stopnjo uporabe folklore, ampak hodi ponekod tudi bolj zakrita pota, s čimer pa njena ekspresivna avtentičnost ni $v$ ničemer zmanjšana. $V$ najslabšem primeru, ki je glede na medij še celo ustreznejši, ostane »samo" glasbeno doživeta, ne pa tudi pojmovno in racionalno spoznana, kar je $\mathrm{v}$ absolutnem smislu $\mathrm{v}$ okviru te umetnosti itak nemogoče. ${ }^{15} \mathrm{Ta}$ in taka vprašanja postajajo vse bolj zaostrena, čim bolj usiha folklorna in ekspresivna opora in čim bolj prehaja glasba $\mathrm{v}$ »čiste " ter v internacionalno nivelizirane in zato navidez dehumanizirane različice glasbenega jezika. Vendar od začetka in pri nekaterih skladateljih to še ni prisotno; tako ne pri skoraj pozabljeni Leskovičevi simfoniji Domovina (1940), pri Simfoniji (1946-49) in simfonični pesnitvi Davnina (1940) Marjana Kozine, kot pri Marijana Lipovška kompozicijah Simfonija (1949-40-70), Domovina (1950), I. in II. rapsodija za violino in orkester $(1955,1962)$, Voznica za klavir (1956), Štiri sporočila za godalni kvartet (1973) - vse dela, katerih bistvene nacionalne sestavine bi po analogiji lahko potegnili iz dosedanjega razpravljanja. ${ }^{16}$

Vprašanja pa se svojevrstno zapletejo, ko se prebrodi rameroma kratka in po glasbenih rezultatih ne ravno bogata faza obnove in socialističnega realizma, ko $s$ koncem petdesetih let slovenski instrumental doživlja vedno nove in nove pretrese postwebernovskih evropskih iskanj. Poteze, ki smo jih označili za slovenske, doživljajo transformacije in retuše, nekatere stopajo $\mathrm{v}$ ozadje, medtem ko se nekatere šele prvič pojavijo na obzorju. Staro se skuša prilagoditi, novemu pa manjka izkušenj in je morda ravno zato tako samozavestno in prodorno, kar samo bogati in șpreminja paleto po nepotrebnem podedovane, a sociološko razložljive slovenske skromnosti.

»Tik pred zdajci« beležimo vredna dela, kot so Uroša Kreka Simfonietta (1951), Primoža Ramovša Sinfonietta (1951), Marijana Lipovška Druga suita za godala (1951), Daneta Škerla Serenada za godala (1952), Jurija Gregorca Sinfonietta (1953). Sam preljubi (neoklasicistični) optimizem, da mu je komaj še verjeti! Če je le-ta za Lipovška samo epizodnega značaja in ga Gregorc obenem še lirično razmehča, mu ostane vseskozi zvest pravzaprav samo Dane Škerl. Za Ramovša in Kreka pa pomenita sočasni simfonični deli razvojno križpotje, na katerem je Ramovš s pastoralnostjo drugega stavka morda celo bolj neposredno kot Krek zadel dah slovenske zemlje. Vendar je poslej Krekova povezanost $\mathbf{z}$ zemljo nezatajljiva: modalnost v Mouvements concertants (1955-67) jo razpre proti Panonski nižini, Bela Krajina se zasluti v še bolj stopnjevani ekspresivnosti

14 Bedina K., Nazori Slavka Osterca o tradiciji v glasbi in o glasbenem nacionalizmu, Muzikološki zbornik III/1967, 94.

15 Supičić I., ib., 130.

16 Prim. op. 3. 
Inventiones ferales (1963). Sublimirani folklorni prebliski gredo tudi v sedemdeseta leta: dahnejo na primer iz Sonate za dve violini (1972) ali iz Sonate za klarinet in klavir (1977), pri čemer geografska določljivost ni vedno eksplicitna. Tako je uvodni solo roga v pihalnem kvintetu Episodi concertanti (1970) neutajljiv klic po elementarnem stapljanju $\mathrm{z}$ naravo, $\mathrm{z}$ gozdovi in vršaci. La journée d'un bouffon za kvintet trobil (1973) je nekoliko trši oreh: vstopno prizivanje glede na zasedbo kar kliče po muziciranju na prostem, medtem ko je časovna in idejna semantika zastavljene norčavosti, melanholije in bria razmeroma polivalentna. Morda je tudi bolje, da je tako; namreč, da je to »pesem brez besed «.

Ramovš je kot starosta povojnega slovenskega avantgardizma seveda šel svojo pot, na kateri vse težje najdemo zgovorne oziroma prevedljive kažipote nacionalnega. Po kompozicijah, kakršni sta Musiques funèbres (1955) ali Koncert za violino, violo in orkester (1961), smo prepuščeni samim sebi: »abstraktnost « skladatelja, »ki gradi iz zvoka samega in zaradi zvoka samega «, ${ }^{17}$ opravi svoje; bolj ali manj očitna primerljivost komponiranega se znotraj in zunaj našega kulturnega prostora skrči na najmanjšo možno mero. Kakor da bi nacionalna nota sploh ne bila več prisotna. In vendar: kaže, da jo je iskati drugod, v potezah, ki jih je bil že nakazal skladateljev kompozicijski učitelj. Ramovš je od šestdesetih let dalje ustvarjalec, ki ga vse zanima, ki se vse upa, ki se ne sramuje »največjih vzponov in zvočnih krikov, kakor tudi ne najpritajenejšega šepetanja ali dolgih mirujočih barvnih linij «, 18 skladatelj, ki ne ostaja v danih okvirih, skladatelj, ki zna in se ne boji premikati gorá zvoka. Kako neslovensko! Ali pa se je slovensko premaknilo? A bolj resno. V čem bi konkretno pri Ramovšu na primer iskali »mediteranskoslovansko varianto avantgardizma «, ${ }^{19}$ bi verjetno laže ugotovil tujec, ki mu je dana potrebna distanca, medtem ko se avtor nagiblje mnenju, da zlasti tovrstna glasba, razen če seveda ni absolutno hermetične narave in sama sebi samozadost$\mathrm{na}$, šele $\mathrm{z}$ neštetokratnim poslušanjem in primerjanjem pridobiva na pomenu, ki je oblikovano $\mathrm{v}$ gradivu in ki se $\mathrm{s}$ poslušanjem in primerjanjem doživlja kot pomen tega abstraktnega oziroma abstraktnejšega zvočnega gradiva. ${ }^{20}$ Sedaj in tukaj mu to in tako razkrivanje še uhaja iz rok. Uhaja mu tudi pri avantgardno usmerjeni generaciji, ki je ob Ramovševih iskanjih izrasla iz nekdanjega Kluba komponistov ljubljanske Akademije za glasbo. Morda še najmanj pri Alojzu Srebotnjaku, ki mu neglede na glasbeni jezik ne manjka vezi s folkloro in kogojevskim neoekspresionizmom; slednja vez velja tudi za Jakoba Ježa, ki vedno znova zna ujeti patinirano slovensko glasbeno preteklost; tu je tudi Ivo Petrić, ki se je iz hindemithovsko-osterčevske igrivosti $\mathbf{v}$ sedemdesetih letih potopil $\mathbf{v}$ široka, deloma aleatorična godalna spletanja $v$ smislu nekakšnega sodobnega, a slovensko dobro preizkušenega neolirizma. Če preskočimo skoraj trajna »zdomca « Janeza Matičiča in Vinka Globokarja, ki predstavljata poseben primer nacionalnega razlaščanja evropske glasbene kulture in zato presegata okvir dane tematike, kaže omeniti vsaj še dva etabiirana skladateja. Prvi je Darijan Božič, $s$ katerim so jazzovski elementi navzlic svojim »ubranim « in »tujerodnim « izhodiščem tudi v resnem instru-

17 Gl. Koncertni list Slovenske filharmonije, 1969/70, št. 7, 7.

$18 \mathrm{Ib}$.

19 Prim. op. 6.

20 Faltin P., Musikalische Bedeutung, Grenzen und Möglichkeiten einer semiotischen Ästhetik, International Review of the Aesthetics and Sociology of Music, Vol. X, No. 1 1978, 5 sl.. 
mentalu dobili slovensko domovınsko pravico. Njegova izpovedna moč pa je predvsem v »akustičnih gledališčih «, teh novodobnih purgatorijih današnjega koncertnega občinstva. Domislekov mu ne manjka, tudi takrat ne, ko v Beli krizantemi (1976) malomestno oziroma primestno (beri: povprečno slovensko) mentaliteto pretresljivo sooči $z$ umetnostjo: harmonika kot simbol »zdravega« slovenstva se $\mathbf{s}$ svojo ponavljajočo usločeno vižo izkaže kot grobar slovenske (glasbene) kulture... Drugi je Lojze Lebič, ki je ob vsem velikem smislu, ki ga izkazuje za vokal, izrazito instrumentalni ustvarjalec. Zanimivo: navzlic sodobnemu zvoku in sodobnim oblikovalnim načelom njegovi glasbi ne primanjkuje še tako sublimirane povednosti. Še več: na vsakem koraku utripa bolj ali manj zastrta slovenskost - od naslovnih značilnosti, mottov, prikritih ali tudi odkritih intervalno-folklornih obratov in instrumentalnih barv do nanovo interpretiranih, ne ravno neznanih občutij in vzdušij - kar kaže, da jo tudi novi zvok ne more in ne bo izrinil.

Ob koncu se seveda postavlja vprašanje, mar niso slovenske nacionalne poteze bolj očitne v kakšni drugi umetnosti; morda v likovni ali v arhitekturi. Kar bi zahtevalo primerjavo, ki še ni bila opravljena. Prav tako se je zavedati dejstva, da (instrumentalna) glasba tudi pri najbolj muzikalnem narodu ne more odsevati vsega. Gotovo obstaja cela vrsta karakterističnih črt, ki jim pač ni mogoče najti glasbenega ekvivalenta. Toda: glede na to, da jih več kot samo slutimo, kaže, da odsevajo celo $v$ instrumentalni glasbi, ne da bi si pri tem domišljali, da je bil s tem zapisom zarisan popoln topografski zemljevid stereotipov slovenskosti. Vprašanje je, če je kaj takega možno, oziroma, če lahko to $z$ glasbo sploh razvozlamo.

\section{SUMMARY}

The tenor of the article is the rather tricky problem of national traits in music. The point in question is brought into focus through the fact that the author of the essay confines himself to instrumental music only. Proceeding from intuitive epitheta as used when characterizing respective elements of Slovene instrumental output as well as from Leonard B. Meyer's idea that 》music may be meaningful because it refers to things outside itself, evoking associations and connotations relative to the world of ideas, sentiments and physical objects «, the inquiry tries to detect those traits, qualities or rather elements - ranging from the choice of titles down to formal and textural niceties - which might be regarded as reflections of national characteristics. These are persued through approximately the last hundred years in the course of which many a trait has no equivalent in music and therefore a complete topographic map of Slovene stereotypes cannot he unfolded by means of (instrumental) music. Which was not, in the last instance, the aim of this essayistic consideration. 